\title{
The Many Paths to Sophia: Toward a Deeper Philosophical Appreciation of Poetry
}

\author{
William A. Welton \\ Kent State University \\ Daniela Elza \\ Simon Fraser University
}

\begin{abstract}
Although the argument against poetry may have had its locus classicus in Plato's Republic, the philosophical qualms against poetry are deeply rooted and are not unique to Plato's philosophy. We begin by considering the reasons why some philosophers once believed that philosophy was superior to poetry, and then we regard some of these prejudices and how they have been debunked in contemporary philosophy. Our main purpose in this paper is to move beyond this inadequate understanding of poetry to a deeper philosophical appreciation of it.
\end{abstract}

Keywords: poetry; philosophy; education

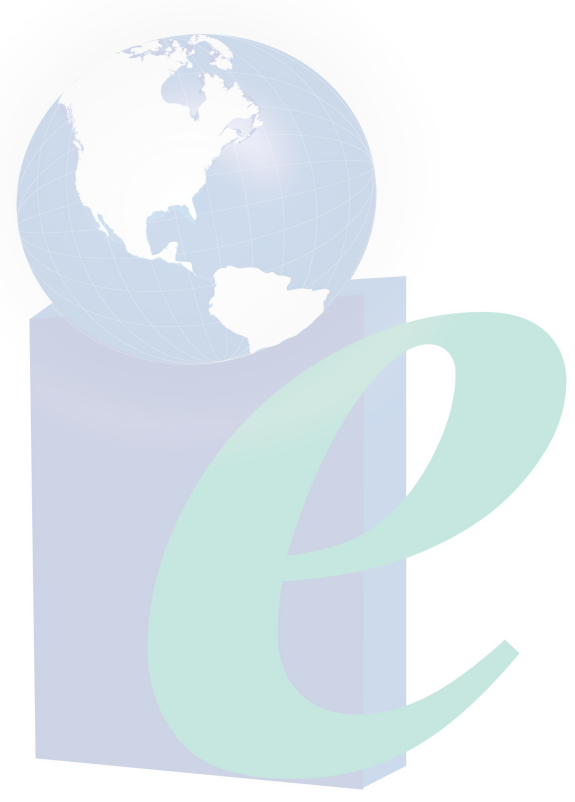




\section{The Many Paths to Sophia: Toward a Deeper Philosophical Appreciation of Poetry}

"Thought is, in fact, the blood around the human heart."

-Empedokles, DK fragment 105

(as cited in Bringhurst, 2007)

At least since Plato spoke of the quarrel between poetry and philosophy in the Republic (a quarrel that he claimed was even then of long-standing; Plato, trans. 1997, Republic 607b-c), there has often been mutual suspicion between the practitioners of these two forms of human insight and inquiry. Philosophical suspicion against poetry is not unique to Plato's philosophy, but part of what he says in the Republic points to the deep roots of a certain prejudice against poetry based on the preeminent importance to philosophy of abstract ideas. In the first section of this paper, The Case Against Poetry, we consider this prejudice; in the next section, Questioning the Case Against Poetry, we discuss the way in which some more recent philosophers defend poetic discourse by questioning some of the assumptions of this view. In the rest of the paper, we explore the philosophical dimensions of poetry for which these newer philosophies make room.

\section{The Case Against Poetry}

Philosophical argument and explanation demand the universal and abstract. Not only does philosophy typically deal in abstract concepts, but deductive argumentation is understood to depend on abstract logical form (making the discipline of formal logic possible). Similar things can be said about inductive arguments that seem to infer conclusions about particular concrete things based on concrete signs. Thus, philosophical thought, and human understanding in general, must deal to some extent with the generalized, the universal, and the abstract. Reason as traditionally understood is supposed to be at home in the medium of abstractions.

Poetry, on the other hand, deals with images that invoke concrete, sensual realities. Poets also use abstractions, but it is not the business of poetry to follow logical implications to see where they lead. Rather the use of metaphor, concrete imagery, representations of particular acts in the sensual world, loom large in poetry; these images might be understood to suggest generalizable situations or might be taken as symbols of universal significance, but in poetry such contemplation is usually mediated through concrete imagery, with no effort to achieve a precise expression of abstract concepts through the discipline of dialectically formed definition.

For Plato (trans. 1997), philosophy appeals to a different, better, more objective part of the mind than does poetry (Republic X, 605a-c and context). According to this view, an account offered in the language of abstraction is more likely to be true and absolute than is a story with concrete, particular images; for the particular and concrete are linked to particular points of view and the relativity and contingency involved with such perspectives. Universality, on the other hand, is thought to produce more reflective and less partisan judgement. It may be acknowledged by the philosopher that unlike mere sensation, poetry and poetic imagination see the universal in the concrete (Aristotle, trans. 1996, Poetics 1451b1-19). Yet even if an image is used as a symbol for a universal, it then has to be interpreted, and thereby, poetry can still be faulted for being more obscure and imprecise than philosophy. Many philosophers are drawn to the purity and simplicity of prose as clearer than poetry-as though poetry's inessential images merely cover the nakedness of what is with sentimental beautification. Poetry may be admitted to be full of richness of meaning, economy of expression, power to evoke emotion, and to exercise autonomous self-expression-but for all that, poetry's claim to truth and clarity must be 
diminished, according to this Platonic view; poetry’s very richness, suggestiveness, and economy of expression means that it is full of ambiguity and imprecision. Either one remains at the level of the concrete image and so never tries to grasp the general truths that philosophy seeks, or one attempts to ascend to the universal by means of an interpretation of concrete symbols that seems somewhat arbitrary, and in any case the general truths grasped by such an interpretation are merely general claims - the imagery, no matter how artful or compelling, has done nothing to establish those claims, offered no evidence for them that goes beyond mere assertion or a manipulation of emotion; or if, in the best case, an abstract argument is suggested by a poem, from the philosopher's point of view it would be much preferable to make the argument explicit and clear from the beginning, that is it would be preferable to philosophize. Such an attitude, at any rate, seems to be what the argument in the Republic would suggest, and it is one that is often held by philosophers unsympathetic to poetry.

From this point of view, it seems that the aim of poetry is different from the aim of philosophy. Philosophers seek the unvarnished truth, subjecting themselves to self-criticism and their ideas to dialectical testing, whereas poetry must serve two masters - truth yes, but above all, aesthetics. Poets want their words to please an audience and to stand in the inviolability of their right to self-expression. According to this view, poets cannot claim to be knowers of the great matters philosophers investigate, for poets do not investigate as philosophers do, through the long, tedious ugliness of argument that appeals only to thought. Philosophy could be used to get at absolute truth, to know the world as it is in itself, to achieve universal and necessary knowledge, and to articulate a timeless, ahistorical, perspective-free reason. Reason itself was seen as some superior faculty set above desire, feeling, and imagination.

\section{Questioning the Case Against Poetry}

It has increasingly become clear to many philosophers that this negative assessment of poetry depended on a limited understanding of philosophical truth, one that attempts to reduce it to a purely logical, cognitive mode. From the point of view of newer, more favourable philosophic views of poetry, the aesthetic realm - the realm of the senses and feelings, of the concrete in its interplay with the universal-is part of a larger, deeper, and more intimate truth, one that philosophy cannot touch without help from poetry. (Interestingly, even Plato constantly uses concrete imagery to make his philosophical points, and situates his arguments within dramas that fit his own description of imitative poetry by representing concrete individuals engaged in specific deeds-although in this case the deeds in question invariably involve philosophical conversation - $\mathrm{a}$ fact that has suggested to some interpreters that Plato himself had a more favourable view of poetry than the arguments of Book 10 of the Republic (trans. 1997) suggest. See, for example, Tanner, 2010).

Through much of the philosophical tradition it was held that philosophy should strive for universal and necessary truths as part of a univocal, absolute description of reality. Whether one saw concepts as intuitions of transcendent Platonic Forms or merely as abstractions formed by the mind on the basis of the raw materials of experience, in either case, the absolute categories of philosophy were intended to be the language of being itself. But through the work of philosophers such as Nietzsche, Heidegger, Wittgenstein, the American pragmatists, William James and John Dewey, and more recently, the American neo-pragmatist, Richard Rorty, and the Italian hermeneuticist, Gianni Vattimo, many philosophers have begun to moderate their claimsby acknowledging the historical contingency of their discourse. In doing so, they have 
abandoned the claims that philosophy is a kind of super-discipline that can set itself up as a tribunal for other areas of culture. Philosophy that has given up claims to be a mirror of nature or the voice of a transhistorical Reason becomes a form of what the Italian philosopher Gianni Vattimo approvingly calls “weak thought” (See Zabala, 2007)—an interpretation that accepts its contingency_or what Rorty (2007) calls "cultural politics"-using the imagination to find proposals for new and better ways to live and to bring them to consideration in the ongoing conversation of culture without hoping ever to bring the conversation to a close ( See also his discussion of Hermeneutics in his earlier work, Rorty, 1979). From the point of view of such a humbled or admirably weak conception of philosophy, the old arguments placing poetry beneath philosophy carry little weight. The different understanding of truth that grows out of these recent philosophies - truth as something that is historically contingent, context-dependent, open-ended, perspectival, and existential or concretely embodied-allows for a greater appreciation of the unique power of poetry by philosophers; a realization that poetry, by virtue of its very form, has always been in a certain sense truer to crucial aspects of truth.

In addition, this newer sort of philosophy has come to appreciate that poetry's creative use of language; its determination to think outside of any box and its yearning to express the freedom of unique experience are needed for opening up the world of experience, essential to philosophy's quest for self-knowledge and meaning. In the remainder of this essay, we attempt a more just philosophical appreciation of poetry as a liberation and opening up of experience, one that involves an inseparable blend of dialogue with the innermost self and the fostering of relationship and communion with the larger world. In the next section, we discuss Rorty's distinction between normalized and non-normalized discourse and how poetry might be seen as such a discourse.

\section{Poetry as Non-normalized, Liberational Discourse}

It is from Rorty (1979/2009) that we take an idea that seems useful in helping us re-think the relation between philosophy and poetry; this idea is Rorty's distinction between two types of discourse: normal versus revolutionary discourse (a distinction that is Rorty's adaptation and generalization of Thomas Kuhn's famous distinction between normal and revolutionary science). On the one hand, there is what Rorty (1979) calls normal discourse, or what we prefer to call normalized discourse - to stress that it is a form of discourse that has been actively subjected to human management, conventions, or norms. Normalized discourse is discourse that is subject to shared agreements, definitions, methods, or criteria that provide clear standards for settling disputes. On the other hand, there is abnormal or revolutionary discourse (which we shall also call non-normalized or liberational); and this is any discourse that is not yet normalized. Rorty (1979) presents the distinction quite simply, as follows:

Normal discourse (a generalization of Kuhn's notion of “normal science”) is any discourse (scientific, political, theological, or whatever) which embodies agreed-upon criteria for reaching agreement; abnormal discourse is any which lacks such criteria. (p.11)

In using the dubious expression abnormal, Rorty (1979/2009) does not intend to disparage nonnormalized discourse; he refers to it as revolutionary and associates it with the kind of therapeutic, edifying philosophy that he valorises (Rorty 1979/2009, p.320). Edification, in Rorty's (1979/2009) sense is “project of finding new, better, more interesting, more fruitful ways 
of speaking," and can consist in "the 'poetic' activity of thinking up such new aims, new words, or new disciplines, followed by...the attempt to reinterpret our familiar surroundings in the unfamiliar terms of our new inventions” ( p.360)._ For Rorty (1979/2009), “edifying discourse is supposed to be abnormal, to take us out of our old selves by the power of strangeness, to aid us in becoming new beings” (p. 360).

Although Rorty's distinction is not intended to be rigid, in general it may be said that mathematics and natural science represent highly normalized discourses, whereas literature and poetry, especially in their most innovative and experimental forms, would be paradigm cases of non-normalized discourse. Science strives for intersubjective agreement and clear criteria for solving practical and theoretical problems; literature may strive for the communication of unique experiences, indeed the pursuit of autonomy and self-creation through having such experiences, and imagining new and better ways to live. Philosophy can move in either direction; some philosophy tries to emulate science by trying to forge new normalized discourses, striving to come up with methods of intersubjective agreement and to form new systems of knowledge on their basis; other philosophy deconstructs normalized discourse, generating abnormal discourse which aims to show there can be new and better ways of thinking and no method or system can have a monopoly on the truth.

No discourse is entirely without norms. Language that fails to heed any shared conventions of spelling, punctuation, grammar, or that depends on no shared assumptions would cease to be communicative, perhaps cease to be language at all. Not one of these rules is sacred; any may be violated. However, at any given point, some rules are followed. Even the highly normalized language of science is not without ambiguities. It is possible for the most rigorous definitions to change over time. Revolutionary discourse breaks out every so often, as a shift in the prevailing paradigm occurs.

Each of these modes of discourse has its legitimate purposes. Normalized discourses are useful for coming to agreement and consensus in certain areas and making us more effective in our pursuit of some shared projects. However, non-normalized discourses both call into question the absolute hegemony of any normalized discourse and make way for the possibility of newer, innovative normalized discourses. They free us to see the world in new ways, thus enabling us to pursue our autonomy, to find and share unique, personal experiences of meaning in the world.

It becomes increasingly apparent that there are many different ways of approaching the world, and that what we call "objectivity" is but one of them. It is not an absolute, not an epitome of consciousness, but a stance in the world. (Evernden, 1985, p. 107)

Both poetry and philosophy can be more or less normalized, but poetry is generally a far freer form of discourse, and in being so, it has a kinship with non-normalized forms of philosophical investigation. Such discourse has an important role to play in our lives. For Bachelard (1964), contemporary poetry introduces freedom in the very body of the language: "As a result poetry appears as a phenomenon of freedom” (p. xxvii).

From this point of view, what is meant by universals or essences in philosophy are only pragmatically useful theoretical constructions, that is, the clear-cut definitions employed in the context of a specific field or even a specific investigation. If normalized thinking becomes alltoo-familiar, poetic thinking may also serve to recontextualize and renew it, giving it new life 
through reflective commentary on its deeper significance-as when poetic appreciations of the findings of science serve to reawaken our sense of the beauty and wonder of science.

It appears the value of the attempt to forge normalized discourses in philosophy does not depend on the effort being successful because it rarely seems to be more than marginally so. The following aphorism of Nietzsche (1878/1996) speaks to this point:

Error of Philosophers: The philosopher believes that the value of his philosophy lies in the whole, the building; posterity discovers it in the bricks with which he built and which are then often used again for better building: in the fact, that is to say, that the building can be destroyed and yet nonetheless possess value as material. (p. 261)

Normalizing philosophers try to build an edifice for the ages, for others to dwell in, imagining that lasting edifice is the value of their philosophy; but the real value in the eyes of others is seen in the raw materials, in the component parts that can be re-used in their own constructions. Liberational discourse takes the form of tearing down these old dwellings, or pointing out their shaky foundations, what they are unable to incorporate, how much of life still goes on outside them. Bachelard (1964) uses a similar image when he speaks of words as little houses, "each with its cellar and garret," where "common sense lives on the ground floor. ...To mount and descend in the words themselves - this is a poet's life. To mount too high or descend too low, is allowed in the case of poets, who bring earth and sky together. Must the philosopher alone be condemned by his peers always to live on the ground floor?" (p. 147) We could think of the ground floor as the world of common-sense, normalized discourse that is challenged by the free (liberational) explorations of poets as they ascend and descend through possibilities of language and perception, and in the process making it home.

Academic study of poetry can often involve a normalizing discourse in its analysis of poetry. Schools or styles of poetry, if they subject the freedom of poetry to the rigidities of an externally-imposed aesthetic, can involve a misplaced attempt at normalization. "Poetry is knowing, but verse is a form, a technique, a device. At worst it is merely a grate through which language is pushed" (Bringhurst, 2007, p. 28). Thus, in school one is more likely to attend to poetry on a superficial level. Form is easier to analyse, so it is likely we will analyse poems into devices and dissect them into techniques. Somewhere along the clinical hallways of school, poetry loses its soul, its potentiality as liberational discourse: that brief ecstatic dance of language before we tie it up in sophisticated and separate disciplines.

Considering poetry in its authentic mode as a discourse essentially freeing, Bringhurst (2007) cautions:

Translators, lawyers, doctors, teachers and engineers, like bakers, potters, and carpenters, all have to be poets in their own way. When they are not, things are apt to go awry. And they do go awry, because professions become institutions, and institutions close their doors and windows, leaving poetry outside. That does no harm to poetry, of course; it only harms the institutions. Outside-meaning outside human management-is the place where poetry lives: in the mountains, in the forest, in the body, in the mind. (p. 74) 
"Outside human management"-we might translate that into the terms we employ here to say "outside the effort to normalize." The poetic consciousness dwells in the freedoms that an institution cannot afford to give. The poetic consciousness is freedom, is an act of emancipation. Bringhurst (2007) begins his book with, “I don't know how poetry knows.” He goes on to say:

Poetry is one among many forms of knowing, and maybe it is knowing in the purest form we know. [...] knowing freed from the agenda of possession and control—knowing in the sense of stepping in tune with being, hearing and echoing the music and heartbeat of being -is what we mean by poetry. (p. 15)

Poetry develops an autonomous way of seeing and shares it with others for the purpose, in part, of encouraging others to develop their own autonomous creativity. Poetry typically seeks not so much to proselytize as to inspire. Thus, it is more akin to that sort of philosophy that does not give in to the impulse to systematize.

What normalized and liberational discourse share is that they are both part of our effort to make sense of the world and to live well in it, in harmony with it. Normalized discourse, as in science or in law, is perfectly legitimate when it understands its limitations and contingency, and when it remains open to critique. Philosophy and science at their best, and poetry at its best, can incorporate the desire to be self-critical, to be open to other points of view, other possibilities, to what nature or the other have to teach us. But such a drive for truth demands of us bravery, humility, openness, and flexibility. It is on this point of willingness to submit to criticism and openness to other ways of seeing things that Socrates' claim "The unexamined life is not worth living” (Plato, trans 1997, Apology, 38a) meets up with Buddhist ideas about detachment and mindfulness and with the Christian idea of loving your neighbour as yourself. What these ideas have in common is a willingness to be open to what is and to respond creatively to it, the willingness to let go of the limitations of one's current perspective or ego, or in other words, a willingness to allow liberational discourse to flourish, to challenge, and even potentially to transform a given normalized understanding of the world. Poets, too, are open to a Socratic awareness of ignorance. In her Nobel lecture titled The Poet and the World, Wislawa Szymborska (1996) says:

Poets, if they're genuine, must also keep repeating “I don't know.” Each poem marks an effort to answer this statement, but as soon as the final period hits the page, the poet begins to hesitate, starts to realize that this particular answer was pure makeshift that's absolutely inadequate to boot. So the poets keep on trying, and sooner or later the consecutive results of their self-dissatisfaction are clipped together with a giant paperclip by literary historians and called their "oeuvre." (para 15)

In ineffective or bad forms of sense-making — such as prejudice, oppressive thinking, and dangerous versions of rhetoric —-we lose sense of our own ignorance. As a result, we make sense of the world in ways that do not work well, engaging in modes of discourse that ignore, cover up, neglect, distort, or force into excessively limited or obscured, reductive categories. At their worst, philosophy and science, and rhetoric and myth, can all fall into these dangerous modes.

Liberational discourse not only liberates the self, but also it demands greater humility of the self; for it also implies a respect for the liberty of the other, and a greater respect for and awareness of the possibilities of being in general. Lilburn (1997) regards poetry as a courteous 
way of seeing. When asked: "Is 'seeing with courtesy' a way to truth," he answers: "It is truth. The thing is more than your name for it and more than your ability to know it" (Lilburn, 1997, p. 135). This idea of truth as a way of approaching, as an attitude, truth as something between us, is a turning toward the other (be that other person, rock, or tree), an opening onto life, a recognition that we are partaking in a sensate and mysterious world that is beyond rationalization, an emancipation of the self where we exist as equal intelligences, and equal beings (Ranciére, 1999). It is an epistemic stance where one learns by leaning into or toward the other, a sympathetic stance, which includes a loving admiration of the other. Lilburn (1997) allows for the existence of this kind of participatory consciousness, saying:

There is consciousness as thief, going in to this thing that is not it and taking stuff out; there is consciousness as stranger, never on the inside. But if this possibility is true there is consciousness as integral or necessary to the thing, participatory. Eros becomes part of cosmology: the tree in order to be this tree and no other tree needs me or you or somebody else to need it, love it, celebrate it. Then it becomes itself in the excitement of human consciousness. (para. 25)

He does not limit this consciousness to poetry; to use his phrase: "there are sorts of prose that are fine vehicles for eros" (final line). Poetry here is conceived as the quality and texture of our thought and attention, as a courteous way of seeing and being in the world. The poem is a testimony for the quality of this attention and participation with the world.

The freedom of poetry as a liberational discourse can be understood through Bachelard's (1969) notion of reverie. Reverie is not a word we talk about much. It is the thing we do when we are not doing anything. It stands in the way of focus, of getting work done, of paying attention. We think of it as "unproductive, impractical, and so completely unempirical as to be considered almost immoral in a society oriented toward pure and sometimes mindless action" (Bachelard, 1969, p. v). Yet, according to Bachlard (1969), it is a place of well-being, a place of alert consciousness, and a place of deep repose: “And it is in reverie that we are free beings" (p. 101)....Isn’t it also in reverie that man is most faithful to himself?” (p. 136) This echoes Ranicére (1999): "Truth settles no conflict in the public place. It speaks to man only in the solitude of his conscience” (p. 90). The reverie Bachelard (1969) explores is poetic reverie. "This is a reverie which poetry puts on the right track, the track an expanding consciousness follows” (p. 6).

The poet's vision, like the phenomenologist's, sees the world in a new way. In seeing the world in a new way, the poet breaks through, or violates, old metaphysical categories and gets in touch with the kind of truth that is an upsurgent presence, an unconcealing in Heidegger's (1993) parlance (p.126). For these reasons, poetry and thinking, poetry and philosophy, are, as Heidegger (1971) says, “in the same neighborhood” (p. 70). ${ }^{1}$ Whether or not speech is poetic has nothing to do with whether or not the words are ordinary or extraordinary. Poets use the words everyone uses, but the poet uses words in extraordinary ways, or in ordinary ways to say extraordinary things. In either case, the extraordinary is there-breaking through the veneer of familiarity that veils the world. When the strange, uncanny, miraculous, marvellous quality of the world as it is-its wonder-breaks through to us, it is a form of truth as unconcealment. 


\section{Poetry and Wonder}

"Wonder lies at the heart of poetry" -Bringhurst (2007, p. 247).

Philosophy begins in wonder; that is why, according to Aristotle, the philosopher is in a way a lover of myths (Aristotle, trans. 1968, Metaphysics, 982b, p. 12-20. See also Plato, trans. 1997, Theaetetus, 155d ). If we accept the traditional view that Western philosophy begins with the pre-Socratic philosophers and their attempts to use reason and naturalistic explanation, as opposed to traditional myth, to explain the world, then one can say that poetry, in the form of myth, came before philosophy. Even some of the pre-Socratic philosophers (eg., Xenophanes, Parmenides, Empedocles) were poets and wrote in verse. It has been suggested that poetry may have been the default form of pre-Socratic philosophy (Osborne, 1998). In ancient Eastern thought there is no clear division between religion and philosophy, between philosophy and poetry. If 'wonder' means the experience of the mystery and majesty of the world, one may say that myths are the first responders to the onset of wonder; and to the extent that myths are poetic, one may conclude that poetry is the most primal response to, and articulation of, wonder. Every religion has scriptures and commentaries that are either through-and-through poetic or at least have poetic elements. It makes sense that when we try to speak about the gods we must speak in poetry, and that when gods speak to us it is generally through poetry. For the divine is extraordinary and miraculous, and yet pervasive, and poetic imagination calls for the extraordinary in the midst of the everyday; poetry opens the mind to the miraculous dimension of existence itself. It is the liminal quality of religion that seems to link it to poetry. Through its imaginative power, poetry opens the thresholds to new experience. This primal relation to wonder also means that poetry is related to philosophy through philosophy's very element, wonder.

Myths are tales that exceed reason, but that also are capable of feeding the soul at every level-including that of reason, by inspiring us to curiosity and reflection. Myth, Bringhurst (2007) suggests, is “an alternative kind of science, i.e., an alternative kind of investigation. It too, in its own way, is a means of understanding and elucidating the nature of the world. It aims, like science, at perceiving and expressing ultimate truths” (p. 64). Mythic stories and poetic narratives bear wonder within them, and wonder is a seed that bears fruit. Reason grows as a further articulation of wonder, as the rational mind elaborates the varieties of questions that occur to it. As reason elucidates what it is trying to know, the fields of inquiry that constitute the subject matter of the sciences begin to be articulated. New answers lead to new questions. Thus, we should beware of supposing that knowledge and wonder are at odds with each other, or that myth and science are at odds. Instead, knowledge opens up wonder, and wonder is never dispelled, but only elaborated by knowledge, for every explanation ultimately terminates in basic notions, which have yet to be explained; some concepts may be so basic that no scientific explanation is ever to be expected. Thus, science, too, helps open up the experience of wonder. Wonder in science shines forth as the beautiful interweaving of knowledge and mystery.

Wonder may never be fully articulated into logos, but it can be known in other ways. We become intimate with it, united with it, in the silence of meditation, in music, religious devotion, ritual, rites, spiritual practices, mystical experience, meaningful activities, sport, dance, and poetry, the most primordial logos, still close to the spirit of music. "Wonder," Evernden (1985) says, "is the absence of interpretation" (p. 139). "To achieve a sense of wonder is to be 
continually surprised. It is tantamount to suspending all assumptions. It is to start over again” (p. 141). In line with the idea that human creativity requires the renewal of liberational discourse, wonder is manifest in an experience to which any previous normalized discourse seems somehow inadequate. Wonder is thus reminiscent of Kant's (1987) notion of an aesthetic idea, an intuition that cannot be fully captured in concepts, thereby provoking the free play of understanding and imagination (pp.182-183). Contrast the sense of certainty that comes along with the mastery of highly normalized discourses - the satisfaction of knowing exactly how the sum comes out; such a feeling of precision, exactness, and competent mastery certainly has its own value. But if certainty is allowed to become too oppressive, it can cover over the mysteries that remain; by taking the mystery out of knowledge, certainty becomes a dead end. Certainty lacks a sense of adventure. It also lacks humility. "Without poetic attention the world could become too clear-it’s dangerous” (Lilburn, 1997, para 28).

Can poetry be more honest in its dealings with language than types of normalizing philosophy generally are? In poetry we are acutely aware of language as inadequate to translate the experience, and are therefore more likely to take it as a pointing, rather than as a precision tool with which reality is dissected. This awareness that the world cannot truly be captured and expressed is a more courteous way of seeing than one finds in traditional metaphysical philosophy. Could this texture of thought be what develops our ecological mind in ways that will allow us to be more in tune with the planet we inhabit, ways in which, as Zwicky (2002) points out, logic, language, and the ego become less central and we are guided "by a profound sense of the extra-logical connectedness of things?” (p. 136) Could such thought afford us to be more at home in the world?

The poetic way of being in the world and the poetic use of language include the salutary awareness that words tend to make rigid, calcify, what is ever flowing. Herein lies the paradox that "what one knows one cannot say, and once said it is no more the same" (Hess, p. 55). Meaning goes beyond words, yet we cannot get at meaning without language. The meanings that constitute a poem are transmissions from a world not reducible to language, yet at the same time manifest only in the medium of language. So, too, the meanings that serve to constitute the very being of the self are somehow, in part, the transmissions from a world beyond the limits of the ego. Thus, the boundaries between self and meaning, and world and language become blurred, and the question of the freedom of poetry leads us to the question of the relation in poetry between the self and the world.

\section{Self and Other in Poetry: Co-creating With (and as Part of) Divine Nature}

Things that do not separately possess certain properties are somehow able to bring about these properties through their interaction; non-living molecules can combine to form life, unconscious neurons can work together to produce consciousness. These new properties, these emergent qualities, seemingly come out of nowhere into the world; a moment before, the emergent quality was nowhere to be seen, but with a momentary combination of previously existing qualities, the new quality pops into being (as if from nowhere). Nothing like the sound of a clap was here in the room before one of us brought our hands together. Nothing like life was in these atoms before they found their ways to weave together into organic compounds and came together into these protoplasmic forms. Nothing like our consciousness was in the matter of our brain before our neural networks began their intricate work. Similarly, nothing like the beauty of a poem was 
here until these marks on the page, these sounds in air, came together in a precise dance to capture a moment of being and produce a magical effect.

In the light of this reflection upon emergent qualities, the relation between consciousness and its objects takes on a new appearance. Consciousness brings together distinct elements of being into new relations, and with those new relations, new qualities emerge. Poetic language brings disparate aspects of reality into strange new juxtapositions, allowing new dimensions of experience, of being, to come into being. Just as each moment, each being, is a flowing together of innumerable rivulets of causality, so the linguistic expression is a sort of channel into which various streams flow to make something wholly new and unforeseen even by the expresser. The text is offered to the reader who enters this conversation brought together in the aesthetic experience of poetic creativity and in the appreciation of poetry. This conversation within poetry itself, the communion of the poet and her subject matter, can then initiate the conversation between the poet and her audience, a conversation that acquires a life of its own that is more than the sum of its participants, and takes them to places that in turn surprise them.

When one seeks, or finds oneself called, to express something new, one enters into an attentive, receptive relation to whatever it is that inspires, to whatever it is that one is trying to say. Then things shape one's consciousness, and mould one's speech. One thereby becomes different, in response to the call of things. Thus, there is no absolute separation between language and its world. No matter how conventional or arbitrary the precise choice of sounds or marks, or the way they are put together, it is always a human response to a world, a human-channeled reaction to a realm beyond our sway-human and world, each a product of otherwise recondite nature. Language is the living history of so many minds and lives; speech connects one with all those who have used one's words before, and with so many other languages through which one's words have evolved.

Language is not a fixed or ideal form, but an evolving medium we collectively inhabit, a vast topological matrix in which the speaking bodies are generative sites, vortices where the matrix itself is continually being spun out of the silence of sensorial experience. (Abram, 1996, p. 84)

We humans are part of our world and are changed by our world. With our change, the world is changed. We see it anew, live it with new eyes, act in it, interact with it in new ways; we make it different. We do participate with things; it is as though they were our guests and we were participating with them in a festival (w)rite.

The relation of subject and object, or self and other, in poetry might also be explored by asking: How do we come to possess our experiences? Experiences must be composed to make sense of them. But is a moment recollected in exactly the same way twice? Crowther (2007) suggests that, "in the very recollection of key Moments another factor comes into play. For our recollections of them are selective; they exaggerate and omit on the basis of who we have become since they occurred” (p. 206). In these moments of recollection, in attempting to make the first translation from world to word, we are also undergoing a change. We write down the moment, with every rewriting and editing of the text/poem, thoughts and words work like scaffolding for each other, a process of making sense, a process of meaning-making. Yagelski (2009) writes, "Our experience of ourselves in the world and the meaning we make of that experience are not separate; an act of meaning making is in effect an act of being” (p. 12). The 
process is a careful back and forth stitching of the inside with the outside. As Skolimowski (1994) says, "Each journey into reality is always a journey into our mind" (p. 31). And Atwood (2002), "Every life lived, is also an inner life, a life created" (p. 7). Our minds are malleable, ever renewing, and hence these recollections shift as the self shifts. It does seem that a key part of this renewal is a stimulating environment, and a will to engage and participate in an everchanging, flowing world.

Thus, poetry is not just an act of perception, but one of active participation. For Bringhurst (2002), "poetry is a quality or aspect of existence. It is the thinking of things" (p. 155). Writing as an ontological act forces one to rethink the connection between language and being, and offers a refreshing alternative to Cartesian separations between self and world, mind and body. (also see Zwicky, 2011). In recent years, the growing attention to poetic inquiry practices within the humanities is a testimony to the growing awareness within the academy of the value of poetry and embodied knowledge and an awareness of the possibility of expressing the universal in the specific (see Prendergast, Leggo, \& Sameshima, 2009; Thomas, Cole, Stewart, 2012; Elza, 2011, 2012; Stewart, 2010).

Poetic attention is crucial in the process of inquiry and that is important to philosophy. Poetic attention can purify our inquiry, can help us loosen our grip, and shed our certainty. It makes us more faithful to our journeys and to ourselves-makes us more courteous, whole, and open. It brings us back to that state of naiveté where Bachelard (1964) tells us is the threshold of knowledge. Dillard (2007) speaks similarly of innocence: "What I call innocence is the spirit's unself-conscious state at any moment of pure devotion to any object. It is at once a receptiveness and a total concentration” (p. 83). Kohák (1984) calls that breed of thinkers whose insights withstood the test of time form Socrates to Husserl "the perennial beginners" (p. xi). They were

taking the sense of lived experience in its primordial immediacy for their subject matter. Their stance was one of wonder, not of sophistication; the task they took was one of articulation-and their virtue was naïveté, a willingness to see before theorizing, to encounter the wonder of being rather than enclose themselves in cunningly devised theories. (Kohák, 1984, p. xi)

In his book The Three Ecologies, Guattari (2007) says, "Life is a work in progress, with no goal in sight, only the tireless endeavor to explore new possibilities, to respond to the chance event - the singular point - that takes us off in a new direction" (p. 12). This is no simple task. To achieve that, one has to be vigilant, attentive, and open to the possibilities of the moment. It is the qualities of attention and the attitude that are critical. To notice opportunities that chance events present is a challenge today, where we are so goal-driven, so schedule and timetable bound, that we become unaware of what is before us, to the sign that something needs attending. Bringhurst (2002) reminds us, "It is not the world's task to entertain us, but ours to take an interest in the world” (p. 172). He goes on to say:

Our minds, our brains, our hearts are grown out of the world, just as buttercups and mushrooms are. The world is us, and we are little replicas and pieces of the world. How could the world be anything other than as interesting as possible to us? Yet all it takes to break that link is to try to control the world, or take it for granted, or ask it not to change or not to complain while we continue to carve it 
up. All it takes - and this is not, evidently, very difficult to do-is to sever the identity of poetry and thinking. (Bringhurst, 2002, p.172)

Through poetic seeing there is an enhanced awareness, an intensification of the interconnection between things. If reality consists in the interconnection and influences of things/events upon each other, then perhaps poetry is an intensification of the very being of things. Writing the poetic consciousness as a way of inquiry into the world (whether you are a philosopher who poeticizes, or a poet who philosophizes). It is a way of leaving the ego behind and exploring the mind that proceeds without an agenda, equipped with the virtue of naïveté and the radical wonder that summons the attention necessary to sustain an open-hearted inquiry into the world. 


\section{References}

Abram, D. (1996). The spell of the sensuous: Perception and language in a more than human world. New York, NY:Pantheon Books.

Aristotle. (1968) Poetics. (L. Golden, Trans.) Englewood Cliffs, N.J.: Prentice-Hall.

Atwood, M. (2002). Negotiating with the dead: A writer on writing. Cambridge, UK: Cambridge University Press.

Bachelard, G. (1964). The poetics of space. (D. Russell, Trans.). Boston, Massachusetts: Beacon Press. (Original work published 1960).

Bachelard, G. (1969). The poetics of reverie: Childhood, language, and the cosmos. (M. Jolas, Trans.). Boston, Massachusettes: Beacon Press. (Original work published 1958)

Bringhurst, R. (2002). Poetry and thinking. In T. Lilburn (Ed.), Thinking and singing: Poetry and the practice of philosophy (pp. 159-172). Ontario, ON: Cormorant Books.

Bringhurst, R. (2007). Everywhere being is dancing: Twenty pieces of thinking. Nova Scotia, Canada: Gaspereau Press.

Crowther, P. (2007). Defining art, creating the cannon: Artistic value in an era of doubt. New York, NY: Oxford University Press.

Dillard, A. (2007). Pilgrim at Tinker Creek. New York, NY: HarperCollins Publishers. (Original work published 1974).

Elza, D. (2011). Pedagogy of the imagination: of non-verifiable truths and other existential celebrations. Unpublished doctoral thesis, Simon Fraser University, Vancouver, British Columbia, Canada.

Elza, D. (2012). The shape of questions. In C. Leggo, E. Hasebe-Ludt, A. Sinner, \& C. Chambers (Eds.), A heart of wisdom: Life writing as empathetic inquiry. New York, NY: Peter Lang Publishing.

Evernden, N. (1985). The natural alien: Humankind and environment (2nd ed.). Toronto, ON: University of Toronto Press.

Guattari, F. (2007). The three ecologies. London, UK: Continuum.

Heidegger, M. (1971). On the way to language (P. D. Hertz, Trans.). New York, NY: Harper \& Row Publishers.

Heidegger, M. (1993). Basic writings_-revised and expanded edition (D. F. Krell, Ed.). San Francisco, CA: HarperSanFrancisco.

Hess, H. (1984). How pictures mean. New York, NY: Pantheon Books.

Kant, I. (1987). Critique of judgment (W. S. Pluhar, Trans.). Indianapolis, IND: Hackett Publishing. 
Kohák, E. (1984). The embers and the stars: A philosophical inquiry into the moral sense of nature. Chicago, IL: The University of Chicago Press.

Kuhn, T. (1970). The structure of scientific revolutions. Chicago, IL: University of Chicago Press.

Lilburn, T. (1997). Listening with courtesy: A conversation with Tim Lilburn. Studies in Canadian Literature, 22(1), pp. 135-144. Retrieve fromhttp://www.lib.unb.ca/Texts/SCL/bin/get.cgi?directory=Vol22_1/\&filename=lil.html

Nietzsche, F. (1996). Human, all too human: A book for free spirits, (R. J. Hollingdale, Trans.). Cambridge, UK: Cambridge University Press. (Original published in 1878).

Osborne, C. (1998). Was poetry the default form of presocratic philosophy? In C. Atherton (Ed.), Form and content in didactic poetry (Nottingham Classical Literature Studies 5). Bari, ITA: Levante.

Plato. (trans. 1997). Complete Works. (J. M. Cooper, Ed.). Indianapolis, IN: Hackett Publishing.

Prendergast, M., Leggo, C., \& Sameshima, P. (Eds.). (2009). Poetic inquiry: Vibrant voices in the social sciences. Rotterdam, NL: Sense Publishers.

Rorty, R. (1979/2009). Philosophy and the mirror of nature. Princeton, NJ: Princeton University Press.

Rorty, R. (2007). Philosophy as cultural politics; philosophical papers (Vol.4). Cambridge, UK: Cambridge University Press.

Skolimowski, H. (1994). The participatory mind: A new theory of knowledge and of the universe. New York, NY: Arcana, Penguin Book Ltd.

Thomas, S., Cole, A., \& Stewart, S. (Eds.). (2012). The art of poetic inquiry. Big Tancook Island, NS: Backalong Books.

Stewart, S. (2010) The grief beneath your mothertongue: Listening through poetic inquiry. LEARNing Landscapes, 4(1), 85-104.

Szymborska, W. (1996, December ). The poet and the world. Nobel Lecture: The Nobel Prize in Literature 1996. http://nobelprize.org/nobel_prizes/literature/laureates/1996/szymborskalecture.html

Tanner, S. (2010). In praise of Plato's poetic imagination. Lanham, MD: Lexington Books.

Yagelski, R. P. (2009, October). A thousand writers writing: Seeking change through the radical practice of writing as a way of being. English Education, 41(1), 6-28.

Zabala, S. (2007). Weakening philosophy: Essays in honor of Gianni Vattimo. Montreal, PQ: McGill-Queen’s University Press.

Zwicky, J. (2002). Poetry and thinking. In T. Lilburn (Ed.), Dream logic and the politics of interpretation (pp. 121-151). Ontario: Cormorant Books.

Zwicky, J. (2011). Lyric philosophy. Kentville, NS: Gaspereau Press. 


\section{Endnotes}

${ }^{1}$ Heidegger explores this theme throughout his essay "The Nature of Language.” 